\title{
Liver markers, prevalence of the metabolic syndrome abnormalities and effect of Roux-en-Y gastric bypass in morbidly obese subjects
}

\author{
Marcadores hepáticos, prevalência de alterações da síndrome metabólica e efeito do bypass \\ gástrico com reconstrução em Y-de-Roux em pacientes obesos mórbidos
}

\author{
Ary Serpa Neto ${ }^{1}$, Felipe Martin Bianco Rossi ${ }^{1}$, Rodrigo Dal Moro Amarante ${ }^{1}$, Marçal Rossi ${ }^{1}$
}

\begin{abstract}
Objectives: To evaluate the relations between liver markers (GGT, ALT and AST) and the metabolic syndrome (and its components) in morbidly obese subjects, and to determine the response of these metabolic factors and hepatic enzymes after weight loss induced by Roux-en-Y gastric bypass. Methods: This study was carried out at a university hospital, in Santo André (SP), Brazil. We evaluated 140 morbidly obese subjects aged from 18 to 60 years submitted to a Roux-en-Y gastric bypass, who were followed for a mean period of 8 months. Patients with a history of heavy drinking, type 1 diabetes, and/or liver disease were excluded. Results: Liver markers, most notably GGT, were strongly associated with metabolic abnormalities, mainly hyperglycemia. The prevalence of type 2 diabetes significantly increased with increasing levels of GGT (highest versus lowest quartile GGT: odds ratio 3.89 [95\%Cl: 1.07-14.17]). Liver markers significantly decreased 8 months after the Roux-en-Y gastric bypass and the reduction of GGT levels were associated with the reduction of glucose levels (Pearson $r=0.286 ; p=0.001$ ). Conclusions: Elevated levels of liver markers, principally GGT, in morbidly obese subjects are associated with metabolic abnormalities. In addition to the well-known benefits of bariatric surgery, Roux-en-Y gastric bypass, reduced the levels of liver markers to the normal range.
\end{abstract}

Keywords: Obesity, morbid; Biological markers; Metabolic syndrome; Anastomosis, Roux-en-Y

\section{RESUMO}

Objetivos: Avaliar as relações entre os marcadores hepáticos (GGT, ALT e TGO) e a síndrome metabólica (e seus componentes) em indivíduos com obesidade mórbida, e determinar a resposta desses fatores metabólicos e enzimas hepáticas após a perda de peso induzida pelo bypass gástrico em Y-de-Roux. Métodos: Estudo realizado em um hospital universitário, localizado em Santo André (SP). Foram avaliados 140 indivíduos com obesidade mórbida, entre 18 e 60 anos de idade, submetidos ao bypass gástrico em Y-deRoux, acompanhados por um período médio de 8 meses. Pacientes com história de alcoolismo pesado, diabetes tipo 1 e/ou doença hepática foram excluídos. Resultados: Os marcadores hepáticos, principalmente GGT, foram fortemente associados a alterações metabólicas, principalmente hiperglicemia. A prevalência de diabetes tipo 2 aumentou significativamente com a elevação dos níveis de GGT [quartil superior versus inferior: odds ratio 3,89 (IC95\%: 1,07-14,17)]. Os marcadores hepáticos diminuíram significativamente 8 meses após o bypass em Y-de-Roux e a redução dos níveis de GGT estava associada à redução dos níveis de glicose (Pearson $r=0,286$; $p=0,001)$. Conclusões: Níveis elevados de marcadores hepáticos, principalmente GGT, em pacientes com obesidade mórbida, estavam associados a alterações metabólicas. Além dos já conhecidos benefícios da cirurgia bariátrica, o bypass gástrico em Y-de-Roux reduziu os níveis dos marcadores hepáticos a valores normais.

Descritores: Obesidade mórbida; Marcadores biológicos; Síndrome metabólica; Anastomose em-Y de Roux

\section{INTRODUCTION}

Metabolic syndrome (MS), characterized by a core set of disorders, including abdominal obesity, dyslipidemia, hypertension, and hyperglycemia, has been shown to be an important predictor of type 2 diabetes mellitus (DM2) and of cardiovascular disease ${ }^{(1)}$. Recent research has provided evidence that a wider constellation of disorders may be part of the MS cluster. These proposed nontraditional components of MS include

Study carried out at Faculdade de Medicina do ABC - FMABC, Santo André (SP), Brazil.

${ }^{1}$ Faculdade de Medicina do ABC - FMABC, Santo André (SP), Brazil.

Corresponding author: Ary Serpa Neto - Avenida Lauro Gomes, 2.000 - Sacadura Cabral - CEP 09060-6300 - Santo André (SP), Brazil - Tel.: 11 4993-5400 - E-mail: aryserpa@terra.com.br

Received on: Apr 11, 2011 - Accepted on: Oct 25, 2011

Conflict of interest: none 
microalbuminuria, subclinical inflammation, and nonalcoholic fatty liver disease (NAFLD) ${ }^{(2,3)}$.

Subjects with NAFLD, which is the most common cause of chronically elevated transaminase levels ${ }^{(4)}$, have been reported to have high prevalence rates of MS and associated disorders ${ }^{(5)}$. Alanine aminotransferase (ALT) is the most specific marker of hepatic dysfunction resulting from the insulin resistance syndrome. Gammaglutamyltransferase (GGT) is considered a sensitive indicator of liver damage, but is not specific ${ }^{(6)}$.

A number of cross-sectional studies showed relation between GGT and ALT and the MS and insulin resistance, suggesting that GGT/ALT may serve as a marker for insulin resistance ${ }^{(7,8)}$. Furthermore, liver markers have been shown to be associated with MS variables in large representative samples of the general population $^{(4,9)}$.

\section{OBJECTIVES}

To examine the cross-sectional relationships between liver markers (GGT, ALT and AST) and the MS (and its components) in morbidly obese subjects; to determine the response of these metabolic factors and hepatic enzymes after weight loss induced by Roux-en-Y gastric bypass (RYGBP); and to evaluate whether liver markers provide useful supplementary markers identifying subjects at a high risk of DM2 and in particular whether they provide further prognostic information in patients with MS.

\section{METHODS}

\section{Institution}

This study was carried out at a University Hospital, in Santo André (SP), Brazil.

\section{Study population}

A total of 140 morbidly obese patients were considered eligible to participate in this study according to the inclusion criteria: body mass index $(\mathrm{BMI}) \geq 40 \mathrm{~kg} /$ $\mathrm{m}^{2}$, age between 18 and 60 years, and no history of liver disease. Patients with a history of heavy drinking (three or more drinks per day) or with type 1 diabetes mellitus (DM1) were excluded. Most patients (68.5\%) were women and the mean BMI was $46.1 \pm 5.4 \mathrm{~kg} / \mathrm{m}^{2}$ $\left(40.0-65.6 \mathrm{~kg} / \mathrm{m}^{2}\right)$.

\section{Study protocol and follow-up}

Pre and postoperative (at 8 months after bariatric surgery) blood samples were taken after a minimum fasting period of 8 hours. BMI is defined as the individual's body weight divided by the square of his/her height. To define MS, we used the International Diabetes Federation (IDF) criteria: waist circumference $\geq 94 \mathrm{~cm}$ in men, $\geq 80 \mathrm{~cm}$ in women or $\mathrm{BMI} \geq 30 \mathrm{~kg} / \mathrm{m}^{2}$; triglycerides levels $\geq 150 \mathrm{mg} / \mathrm{dL}(1.7 \mathrm{mmol} / \mathrm{L})$ and/or specific treatment; HDL-C levels $<40 \mathrm{mg} / \mathrm{dL}(1 \mathrm{mmol} / \mathrm{L})$ in men, $<50 \mathrm{mg} / \mathrm{dL}(1.3 \mathrm{mmol} / \mathrm{L})$ in women and/or specific treatment; fasting glucose $\geq 100 \mathrm{mg} / \mathrm{dL}(5.6 \mathrm{mmol} / \mathrm{L})$ and/ or DM2 patient; systolic blood pressure $\geq 130 \mathrm{mmHg}$, diastolic blood pressure $\geq 85 \mathrm{mmHg}$ and/or specific treatment. The individual must present at least three of the five risk factors to be diagnosed with MS.

The obese patients underwent laparoscopic RYGBP and after 8 months all tests were repeated. RYGBP is a mixed technique that is more restrictive and less malabsorptive. Its main characteristics are the formation of gastric "pouch" $(15 \pm 5 \mathrm{~mL})$, an alimentary loop of $100 \mathrm{~cm}$, a biliopancreatic loop of 60 $\mathrm{cm}$, and a common loop.

\section{Statistical methods}

Data were first tested for normal distribution with the Kolmogorov-Smirnoff test. For cross-section comparisons, concentration of liver markers between those with and without baseline MS and its components were compared using ANCOVA adjusted for age, sex, and ethnicity. The patients were divided into four equal quartiles on the basis of ALT, AST, AST-to-ALT ratio, and GGT distributions, and linear regression analysis was used to test for trends across the four groups fitting quantitative variables for the four groups.

For prospective analyses, baseline means (with standard deviation - SD) were calculated for subjects by follow-up with $t$ tests, Wilcoxon tests, or $\chi^{2}$ tests. The association between liver markers with anthropometric and metabolic variables was evaluated using Pearson's correlation analysis controlled for age, ethnicity, and sex. Multivariate logistic regression models were used to assess associations of liver markers with the risk of prevalent MS and with its improvement after weight loss, taking into account potential confounders. Each liver marker was modeled as either a continuous variable (with risk expressed per SD increase in the natural log of the marker) or as a categorical variable, comparing risk among those in the fourth quartile versus those in the first quartile. Two models were constructed for each liver marker: in model A, adjustments were made only for age; and in model $\mathrm{B}$, for age, sex and ethnicity. It has been pointed out that the AST-to-ALT ratio may be informative in differentiating alcoholic versus nonalcoholic liver disease (subjects with NAFLD having a ratio below 1), and thus this ratio 
was considered an additional exposure variable ${ }^{(10)}$. We evaluated the degree to which liver markers predicted improvement of MS after RYGBP using logistic regression.

All statistical analyses were made with the statistical software package Statistical Package for the Social Science (SPSS), version 16.0 (Chicago, IL) and MedCalc software. Statistical significance was considered at $\mathrm{p}<0.05$.

\section{RESULTS}

Table 1 shows the baseline characteristics by quartiles of the GGT, ALT, and AST distributions. With the exception of the white cell count, all the metabolic risk factors significantly increased with increasing GGT levels, whereas HDL levels decreased with it. The prevalence of diabetes and hypertension also increased with increasing levels of GGT. ALT was significantly associated with glucose levels and with diabetes prevalence, but showed a significant inverse relationship with the white cell count. AST was associated only with glucose levels. The prevalence of MS did not correlate with increasing levels of GGT, ALT, or AST. However, GGT and AST increased significantly with the increasing number of metabolic abnormalities ( $\mathrm{p}=0.003$ and $\mathrm{p}=0.048$, respectively). Mean GGT values for those with $1,2,3,4$, and 5 abnormalities were $31.8,33.7,38.0,64.0$, and 51.8 units/L, respectively, and for AST the corresponding means were 23.9, 27.4, 27.4, 29.6, and 32.4 units/L, respectively (Table 2).

MS disorders, when assessed individually, were characterized by significant differences only in GGT, before bariatric surgery (Table 2). After surgery no liver marker differed in subjects with MS or metabolic disorders assessed individually. Some situations approached significance, however, due to the median

Table 1. GGT, AST, ALT and metabolic and cardiovascular risk factors

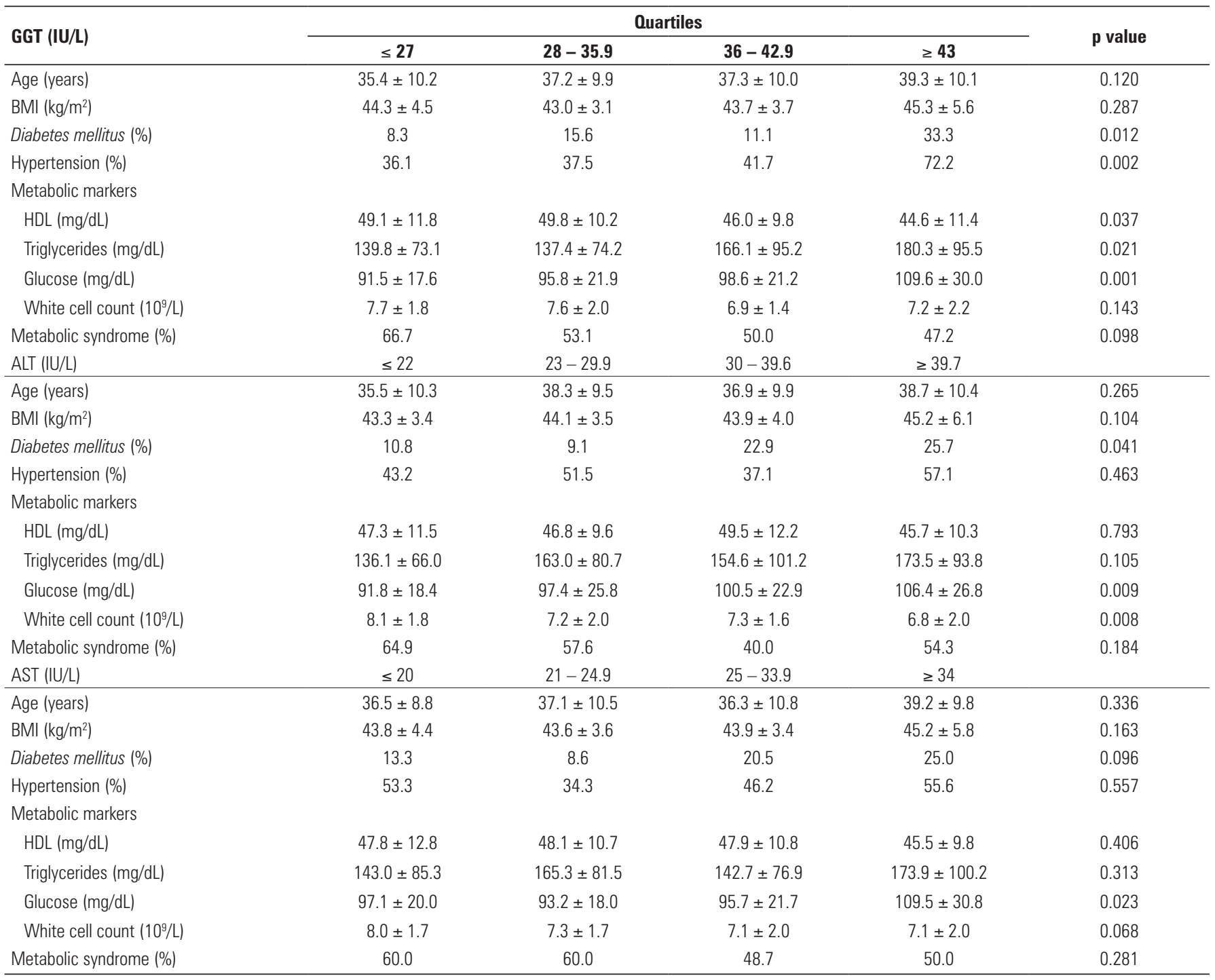

\footnotetext{
$p$ value: trend across groups (linear regression); BMl: body mass index.
} 
Table 2. Concentrations of liver markers in morbidly obese subjects with and without IDF-defined metabolic syndrome and its components at baseline and after 8 months of Roux-en-Y gastric bypass

\begin{tabular}{|c|c|c|c|c|c|}
\hline Liver markers & Yes/No & AST (IU/L) & ALT (IU/L) & GGT (IU/L) & AST-to-ALT ratio (IU/L) \\
\hline \multicolumn{6}{|c|}{ Before Roux-en-Y gastric bypass } \\
\hline \multirow[t]{2}{*}{ IDF metabolic syndrome } & No & $28.1 \pm 10.6$ & $33.6 \pm 11.6$ & $41.0 \pm 22.1$ & $0.86 \pm 0.22$ \\
\hline & Yes & $27.5 \pm 12.4$ & $34.3 \pm 21.2$ & $41.2 \pm 35.2$ & $0.90 \pm 0.33$ \\
\hline \multirow[t]{2}{*}{ Fasting hyperglycemia } & No & $27.0 \pm 11.8$ & $32.5 \pm 18.6$ & $35.8 \pm 19.1$ & $0.91 \pm 0.30$ \\
\hline & Yes & $29.3 \pm 11.2$ & $36.6 \pm 14.9$ & $50.6 \pm 41.6$ & $0.84 \pm 0.24$ \\
\hline \multirow[t]{2}{*}{ Elevated triglyceride } & No & $27.0 \pm 12.3$ & $31.8 \pm 18.2$ & $38.9 \pm 35.0$ & $0.92 \pm 0.31$ \\
\hline & Yes & $28.6 \pm 10.9$ & $36.1 \pm 16.5$ & $43.3 \pm 23.8$ & $0.85 \pm 0.25$ \\
\hline \multirow[t]{2}{*}{ Reduced HDL } & No & $27.3 \pm 9.2$ & $34.6 \pm 15.1$ & $37.2 \pm 21.3$ & $0.87 \pm 0.33$ \\
\hline & Yes & $28.2 \pm 13.2$ & $33.5 \pm 19.0$ & $44.0 \pm 34.6$ & $0.89 \pm 0.24$ \\
\hline \multirow[t]{2}{*}{ Hypertension } & No & $27.4 \pm 12.0$ & $33.1 \pm 18.9$ & $35.3 \pm 17.6$ & $0.89 \pm 0.25$ \\
\hline & Yes & $28.3 \pm 11.2$ & $34.9 \pm 15.7$ & $47.7 \pm 38.5^{\llbracket}$ & $0.87 \pm 0.31$ \\
\hline \multicolumn{6}{|c|}{ After Roux-en-Y gastric bypass } \\
\hline \multirow[t]{2}{*}{ IDF metabolic syndrome } & No & $21.2 \pm 8.4$ & $21.6 \pm 12.0$ & $21.5 \pm 16.2$ & $1.08 \pm 0.42$ \\
\hline & Yes & $26.8 \pm 9.9$ & $24.4 \pm 12.7$ & $35.3 \pm 25.4$ & $1.29 \pm 0.67$ \\
\hline \multirow[t]{2}{*}{ Fasting hyperglycemia } & No & $21.8 \pm 8.8$ & $22.0 \pm 12.0$ & $22.5 \pm 17.8$ & $1.09 \pm 0.42$ \\
\hline & Yes & $22.8 \pm 8.0$ & $21.6 \pm 13.9$ & $37.6 \pm 18.6$ & $1.51 \pm 1.11$ \\
\hline \multirow[t]{2}{*}{ Elevated triglyceride } & No & $21.7 \pm 8.5$ & $21.9 \pm 11.8$ & $23.0 \pm 17.3$ & $1.09 \pm 0.45$ \\
\hline & Yes & $25.6 \pm 12.6$ & $23.6 \pm 17.0$ & $24.8 \pm 29.6$ & $1.33 \pm 0.63$ \\
\hline \multirow[t]{2}{*}{ Reduced HDL } & No & $21.3 \pm 7.6$ & $23.9 \pm 15.4$ & $22.1 \pm 15.3$ & $0.99 \pm 0.29$ \\
\hline & Yes & $22.2 \pm 9.2$ & $20.9 \pm 9.8$ & $23.6 \pm 19.2$ & $1.17 \pm 0.52$ \\
\hline \multirow[t]{2}{*}{ Hypertension } & No & $21.6 \pm 8.9$ & $22.0 \pm 12.5$ & $21.9 \pm 17.8$ & $1.08 \pm 0.44$ \\
\hline & Yes & $23.7 \pm 7.4$ & $21.7 \pm 9.33$ & $29.4 \pm 18.1$ & $1.23 \pm 0.58$ \\
\hline
\end{tabular}

Adjusted for age, sex and ethnicity. $p<0.05$. IDF: International Diabetes Federation.

number of patients and the restrictive effect of the model (sex, age, and ethnicity), significance was not reached.

Associations of liver markers with anthropometric and metabolic variables in morbidly obese patients before and after RYGBP are analyzed. Before surgery AST, ALT, and GGT levels showed positive correlations with fasting glucose, GGT showed an inverse correlation with HDL, ALT showed and inverse correlation with the white cell count, and the AST-to-ALT ratio showed a positive correlation with the white cell count. The magnitude of these associations was strongest for GGT, especially for fasting glucose and HDL. After surgery, only age correlated with liver markers.

Prevalence rates and odds ratio of DM2 by the four groups of ALT, GGT, and AST, using those in the lowest quartile as the reference group, are analyzed. Only GGT values, when adjusted for age, were significantly predictive of DM2. We further examined the relation, adjusting for sex, ethnicity, and age. Such adjustment, as shown in table 2 column $\mathrm{B}$, reduced the risk to levels below statistical significance. On a receiver operating characteristic curve (ROC curve), GGT showed the larger area when compared with AST and ALT (0.670, 0.627, and 0.639, respectively) (Figure 1).

In the analysis of liver markers and prediction of individual MS components, only GGT values were

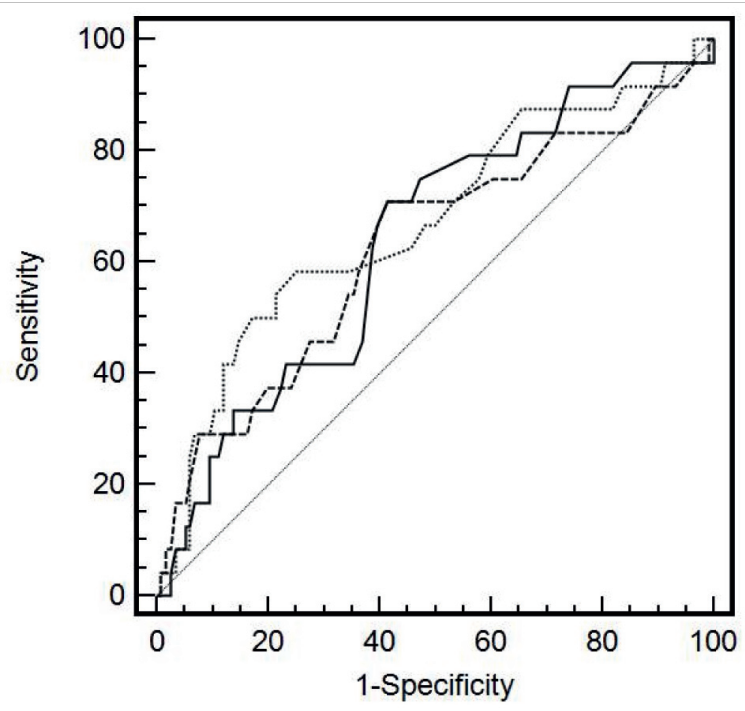

Figure 1. Receiver-operating characteristic curve (ROC) for type 2 diabetes diagnosis. AUC for AST (0.627 [0.541 - 0.707]), ALT (0.639 [0.554 - 0.718]) and GGT (0.670 [0.585 - 0.747]). Comparisons of AUC: AST versus ALT $(p=0.629)$, AST versus GGT $(p=0.879)$ and ALT versus GGT $(p=0.798)$. GGT $(\neg \ldots)$, ALT (__ ) and AST (---)

significantly associated with prevalent hypertension. These associations were significant regardless of whether the exposures were modeled as continuous (risk per SD increase: 1.23 [1.02 - 1.33]) or categorical variables (quartile 4 versus quartile 1: 3.95 [1.33 - 11.69]). 
Eight months after surgery, all liver markers (with the exception of bilirubin) showed a significant decrease, as shown in table 3 . The drop was more accentuated in GGT, followed by ALT. The AST-toALT ratio showed an inverse ratio before surgery (0.88 versus 1.11$)$. After surgery, the $\triangle \mathrm{BMI}$ correlated with $\triangle$ MSFactors (Pearson $\mathrm{r}=0.195 ; \mathrm{p}=0.021$ ) and the $\Delta$ GGT correlated with $\Delta$ Glucose (Pearson $\mathrm{r}=$ $0.286 ; \mathrm{p}=0.001)$.

Table 3. Liver markers before and eight months after Roux-en-Y gastric bypass

\begin{tabular}{lccc}
\hline Markers & Before RYGB & After RYGB & p value* $^{*}$ \\
\hline ALT (IU/L) & $33.99 \pm 17.47$ & $22.00 \pm 12.09$ & $<0.0001$ \\
AST (IU/L) & $27.85 \pm 11.65$ & $21.92 \pm 8.75$ & $<0.0001$ \\
GGT (IU/L) & $41.15 \pm 29.9$ & $23.10 \pm 17.99$ & $<0.0001$ \\
AST-to-ALT ratio & $0.88 \pm 0.28$ & $1.11 \pm 0.46$ & $<0.0001$ \\
Bilirubin (mg/dL) & $0.61 \pm 0.52$ & $0.62 \pm 0.41$ & 0.870 \\
\hline
\end{tabular}

* Paired-samples $t$ Test.

RYGBP: Roux-en-Y gastric bypass.

Table 4 and figure 2 show sensitivity and specificity for selected threshold values of ALT, GGT, and AST predicting improvement of the MS 8 months after the RYGBP in morbidly obese subjects. The receiver operating characteristic analyses suggested AST, ALT, and GGT cut-off values of 23, 33, and 31 IU/L with corresponding sensitivities of $51.4,64.2$, and $44.2 \%$. The area under the curve for the three markers was similar.

Table 4. Sensitivity and specificity for selected thresholds of GGT, ALT and AST for predicting metabolic syndrome improvement

\begin{tabular}{|c|c|c|c|}
\hline Markers & Sensitivity (95\%CI) & Specificity (95\%CI) & AUC $(95 \% \mathrm{CI}) *$ \\
\hline GGT (IU/L) & & & $0.56(0.47-0.64)$ \\
\hline Threshold 27 & $31.4(20.9-43.6)$ & $80.0(68.7-88.6)$ & \\
\hline Threshold 35 & $50.0(37.8-62.2)$ & $52.8(40.6-64.9)$ & \\
\hline Threshold 43 & $77.1(65.6-86.3)$ & $28.5(18.4-40.6)$ & \\
\hline Threshold 54 & $84.2(73.6-91.9)$ & $18.5(10.3-29.7)$ & \\
\hline Threshold $31^{\pi}$ & $44.2(32.4-56.7)$ & $70.0(57.9-80.4)$ & \\
\hline ALT (IU/L) & & & $0.57(0.48-0.65)$ \\
\hline Threshold 22 & $32.8(22.1-45.1)$ & $80.0(68.7-88.6)$ & \\
\hline Threshold 30 & $58.5(46.2-70.2)$ & $58.5(46.2-70.2)$ & \\
\hline Threshold 40 & $75.7(64.0-85.2)$ & $21.4(12.5-32.9)$ & \\
\hline Threshold 52 & $87.1(77.0$ - 93.9) & $8.5(3.2-17.7)$ & \\
\hline Threshold 33" & $64.2(51.9-75.4)$ & $52.8(40.6-64.9)$ & \\
\hline AST (IU/L) & & & $0.55(0.46-0.63)$ \\
\hline Threshold 20 & $31.4(20.9-43.6)$ & $78.5(67.1-87.5)$ & \\
\hline Threshold 25 & $55.7(43.3-67.6)$ & $54.2(41.9-66.3)$ & \\
\hline Threshold 35 & $78.5(67.1-87.5)$ & $18.5(10.3-29.7)$ & \\
\hline Threshold 40 & $90.0(80.5-95.9)$ & $12.8(6.1-23.0)$ & \\
\hline Threshold 23" & $51.4(39.2-63.6)$ & $64.2(51.9-75.4)$ & \\
\hline
\end{tabular}

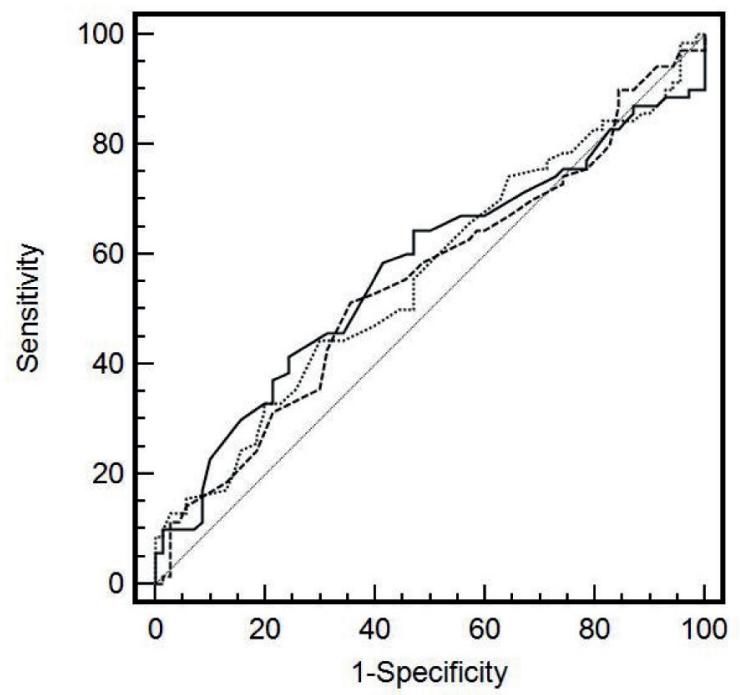

Figure 2. Receiver-operating characteristic curve (ROC) for metabolic syndrome improvement after Roux-en-Y gastric bypass. Comparisons of AUC: AST versus $\operatorname{ALT}(p=0.826)$, AST versus GGT $(p=0.531)$ and ALT versus GGT $(p=0.658)$. $\operatorname{GGT}(\neg \ldots), \operatorname{ALT}\left(\_\right.$) and AST (---)

\section{DISCUSSION}

In the present study we documented, among morbidly obese subjects, significant cross-sectional associations of liver markers, primarily GGT, with metabolic abnormalities, most notably fasting hyperglycemia. Furthermore, at baseline, GGT and ALT levels increased significantly with the increase in number of metabolic abnormalities. Also, we demonstrated that concentrations of GGT were associated with an almost fourfold increased in DM2 prevalence and threefold increase in hypertension prevalence after adjustment for age. In contrast, significant associations with ALT/ AST and metabolic abnormalities were not seen in the multivariate analysis. Finally, liver markers significantly decreased 8 months after the RYGBP, and the reduction of GGT levels was associated with the reduction of glucose levels.

In earlier results, our group showed the beneficial effects of RYGBP in $\mathrm{MS}^{(11,12)}$ and renal function of morbidly obese subjects ${ }^{(13)}$. However, as demonstrated by prior studies, we showed that RYGBP can reduce liver markers to normal levels ${ }^{(14-16)}$. Obesity is a major risk factor for the development of fatty liver disease, and several studies have associated elevated liver enzymes, obesity, and DM2(17). A growing body of evidence also supports the notion that NAFLD is a feature of the MS and that the elevations of liver markers found in this situation, particularly of ALT, are prospectively associated with incident DM2, an important sequel of the $\mathrm{MS}^{(9,18-21)}$.

There are a number of possible mechanisms to explain the associations of liver markers with MS and its factors. First, these markers are known to be significantly correlated with increased hepatic fat content, a disorder 
that has detrimental effects on components of the $\mathrm{MS}^{(22)}$. It has been demonstrated that hepatic fat content, directly measured using proton spectroscopy, is associated with several features of insulin resistance independent of body weight. In particular, hepatic fat was associated with defects in the suppression by insulin of endogenous glucose production $^{(23)}$, which is noteworthy in the context of our results showing that all livers markers were related to fasting hyperglycemia. It is also possible that these associations reflect more generalized insulin resistance.

Fat accumulation in the liver can stimulate cytokine production, and it was found that inflammatory cytokines, such as tumor necrosis factor-alpha (TNF- $\alpha$ ) and interleukin-6(IL-6) can influence fatty acid metabolism in the liver and predispose to the formation of fatty liver ${ }^{(24)}$. Thus, another possible mechanism is that elevated liver enzymes may reflect inflammation, which in turn impairs insulin signaling in both the liver and other organs. Inflammation has been associated with the development of diabetes ${ }^{(25)}$. It has also been suggested that GGT might be an early marker of oxidative stress ${ }^{(26,27)}$. Inflammation is one manifestation of oxidative stress, and the pathways that generate the mediators of inflammation, such as adhesion molecules and interleukins, are all induced by oxidative stress ${ }^{(28)}$. This may explain the association between inflammation, which might reveal nonalcoholic steatohepatitis, and GGT.

The contribution of the present study is the demonstration that liver markers, mainly GGT, are significantly associated with metabolic abnormalities and that GGT also correlates with DM2 and hypertension prevalence in a well-characterized multiethnic cohort of morbidly obese subjects. The weight loss induced by RYGBP can reduce liver markers to levels in the normal range and this decline, in GGT, is associated with an improvement in glucose metabolism. The main limitation of our study is the number of patients, which hinders the finding of a statistically significant result in a very restricted logistic regression model.

\section{CONCLUSIONS}

Elevated levels of liver markers, principally GGT, in morbidly obese subjects are associated with metabolic abnormalities. In addition to the well-known benefits of bariatric surgery, Roux-en-Y gastric bypass, reduced the levels of liver markers to the normal range.

\section{REFERENCES}

1. Sattar N, Gaw A, Scherbakova O, Ford I, O'Reilly DS, Haffner SM, et al. Metabolic syndrome with and without C-reactive protein as a predictor of coronary heart disease and diabetes in the West of Scotland Coronary Prevention Study. Circulation. 2003;108(4):414-9.
2. Mulhall BP, Ong JP, Younossi ZM. Non-alcoholic fatty liver disease: an overview. J Gastroenterol Hepatol. 2002;17(11):1136-43.

3. Serpa Neto A, Rossi FM, Amarante RD, Buriti NA, Rossi M. Impact of plasmatic lipids in glycemic control and its influence in the cardiometabolic risk in morbidly obese subjects. Arq Bras Endocrinol Metabol. 2009;53(6):747-54.

4. Clark JM, Diehl AM. Nonalcoholic fatty liver disease: an underrecognized cause of cryptogenic cirrhosis. JAMA. 2003;289(22):3000-4.

5. Marchesini G, Brizi M, Bianchi G, Tomassetti S, Bugianesi E, Lenzi M, et al. Nonalcoholic fatty liver disease: a feature of the metabolic syndrome. Diabetes. 2001;50(8):1844-50.

6. Penn R, Worthington DJ. Is serum gamma-glutamyltransferase a misleading test? Br Med J (Clin Res Ed). 1983;286(6364):531-5.

7. Rantala AO, Lilja M, Kauma H, Savolainen MJ, Reunanen A, Kesäniemi YA. Gamma-glutamyl transpeptidase and the metabolic syndrome. J Intern Med. 2000;248(3):230-8.

8. Jeong SK, Nam HS, Rhee JA, Shin JH, Kim JM, Cho KH. Metabolic syndrome and ALT: a community study in adult Koreans. Int J Obes Relat Metab Disord. 2004;28(8):1033-8.

9. Liangpunsakul S, Chalasani N. Unexplained elevations in alanine aminotransferase in individuals with the metabolic syndrome: results from the third National Health and Nutrition Survey (NHANES III). Am J Med Sci. 2005;329(3):111-6.

10. Hunt KJ, Resendez RG, Williams K, Haffner SM, Stern MP; San Antonio Heart Study. National Cholesterol Education Program versus World Health Organization metabolic syndrome in relation to all-cause and cardiovascular mortality in the San Antonio Heart Study. Circulation. 2004;110(10):1251-7.

11. Rossi M, Barretto Fereira da Silva R, Chaves Alcântara G Jr, Regina PF, Martin Bianco Rossi F, Serpa Neto A, et al. Remission of metabolic syndrome: a study of 140 patients six months after Roux-en-Y gastric bypass. Obes Surg. 2008;18(5):601-6.

12. Rossi M, Serpa Neto A, Rossi FM, Amarante RD, Alcântara GC Jr, Silva RB, et al. Percentage of excess BMl lost correlates better with improvement of metabolic syndrome after Roux-en-Y gastric bypass in morbidly obese subjects: anthropometric indexes and gastric bypass. Surg Obes Relat Dis. 2009;5(1):11-8.

13. Serpa Neto A, Bianco Rossi FM, Dal Moro Amarante R, Alves Buriti N, Cunha Barbosa Saheb G, Rossi M. Effect of weight loss after Roux-en-Y gastric bypass, on renal function and blood pressure in morbidly obese patients. $J$ Nephrol. 2009;22(5):637-46.

14. Kral JG, Thung SN, Biron S, Hould FS, Lebel S, Marceau S, et al. Effects of surgical treatment of the metabolic syndrome on liver fibrosis and cirrhosis. Surgery. 2004;135(1):48-58.

15. Dixon JB, Bhathal PS, Hughes NR, O'Brien PE. Nonalcoholic fatty liver disease: improvement in liver histological analysis with weight loss. Hepatology. 2004;39(6):1647-54.

16. Andrade AR, Cotrim HP, Alves E, Soares D, Rocha R, Almeida A, et al. Nonalcoholic fatty liver disease in severely obese individuals: the influence of bariatric surgery. Ann Hepatol. 2008;7(4):364-8.

17. Nannipieri M, Gonzales C, Baldi S, Posadas R, Williams K, Haffner SM, et al. Liver enzymes, the metabolic syndrome, and incident diabetes: the Mexico City diabetes study. Diabetes Care. 2005;28(7):1757-62.

18. Clark JM, Brancati FL, Diehl AM. The prevalence and etiology of elevated aminotransferase levels in the United States. Am J Gastroenterol. 2003;98(5):960-7.

19. Perry IJ, Wannamethee SG, Shaper AG. Prospective study of serum gammaglutamyltransferase and risk of NIDDM. Diabetes Care. 1998;21(5):732-7.

20. Nakanishi N, Nishina K, Li W, Sato M, Suzuki K, Tatara K. Serum gammaglutamyltransferase and development of impaired fasting glucose or type 2 diabetes in middle-aged Japanese men. J Intern Med. 2003; 254(3):287-95. 
21. Lee DH, Jacobs DR Jr, Gross M, Kiefe Cl, Roseman J, Lewis CE, et al. Gammaglutamyltransferase is a predictor of incident diabetes and hypertension: the Coronary Artery Risk Development in Young Adults (CARDIA) Study. Clin Chem. 2003;49(8):1358-66.

22. Browning JD, Szczepaniak LS, Dobbins R, Nuremberg P, Horton JD, Cohen $\mathrm{JC}$, et al. Prevalence of hepatic steatosis in an urban population in the United States: impact of ethnicity. Hepatology. 2004;40(6):1387-95.

23. Seppälä-Lindroos A, Vehkavaara $S$, Häkkinen AM, Goto T, Westerbacka $J$, Sovijärvi A, et al. Fat accumulation in the liver is associated with defects in insulin suppression of glucose production and serum free fatty acids independent of obesity in normal men. J Clin Endocrinol Metab. 2002;87(7):3023-8.
24. Day CP, Saksena S. Non-alcoholic steatohepatitis: definitions and pathogenesis. J Gastroenterol Hepatol. 2002;17(Suppl 3)S377-84.

25. Pradhan AD, Manson JE, Rifai N, Buring JE, Ridker PM. C-reactive protein, interleukin 6, and risk of developing type 2 diabetes mellitus. JAMA. 2001;286(3):327-34.

26. Lee DH, Jacobs DR Jr. Association between serum gamma-glutamyltransferase and C-reactive protein. Atherosclerosis. 2005;178(2):327-30.

27. Lee DH, Ha MH, Kim JH, Christiani DC, Gross MD, Steffes M, et al. Gammaglutamyltransferase and diabetes--a 4 year follow-up study. Diabetologia. 2003:46(3):359-64.

28. Hotamisligil GS. Inflammatory pathways and insulin action. Int J Obes Relat Metab Disord. 2003;27(Suppl 3)S53-5. 